\title{
Hate Fuel: On the Relationship Between Local Government Policy and Hate Group Activity
}

\author{
Sean E. Mulholland \\ Eugene W. Stetson School of Business and Economics \\ Mercer University
}

\begin{abstract}
Though often joined for ideological reasons, hate groups provide services for their members. Many of these services are substitutes for government services although others may be complements. Therefore, increases in the quality or quantity of government-provided substitutes may lower the marginal benefit of participating in an active hate group. Conversely, government supplied complements may serve to sustain active hate groups by reducing the negative effect signaling membership may have on labor market opportunities. The fixed effect logistic panel estimation results from 2002 to 2007 suggest that lowering the poverty rate reduces the likelihood that an active hate groups is present. However, using welfare as a means to ease the plight of those less fortunate is associated with an increase in probability a hate group is active within a county.
\end{abstract}

\section{Introduction}

According to the Southern Poverty Law Center (SPLC), an authority on hate group activity, the number of active hate group chapters in the United States increased from 474 in 1997 to 888 in 2007. Figure 1 depicts this rise in hate group activity. ${ }^{1}$ While some types of hate groups have experienced a decline in the number of active hate group chapters, Figure 2 depicts the slow and steady increase in the total number of active Ku Klux Klan, Neo-nazi, and Racist Skinhead chapters and Christian Identity Churches across the United States. Although previous studies have focused on economic conditions, demographics, and history as reasons for hate group activity, few have addressed the possible link between government provided services and the choice to form or join a hate group. ${ }^{2}$

\footnotetext{
${ }^{1}$ The number of groups and the number of affiliations have changed over time. The hate groups included in this analysis from 2002 to 2007 are: the Ku Klux Klan, neo-Nazis, Skinheads, and Christian Identity Churches.

${ }^{2}$ For a discussion of historical literature and a fresh look at old analyses, see Green, Glaser, and Rich (1998)
} 
While it is clear that those seeking to join such groups often do so for ideological reasons, hate group membership also provides services that may substitute for various government services. Therefore, increases in the quality or quantity of government-provided services may lower the marginal benefit of participating in an active hate group. However, it may also be the case that government supplied goods and services may serve to sustain active hate groups by reducing the negative wage impact members face through reductions in labor market opportunities. This paper seeks to determine if counties with active hate groups are able to lower the level of intolerance within their county and thus reduce the presence of hate group activity by altering local government policy.

Using county level panel data from the United States for 2002 and 2007 and controlling for unobserved county-level time-invariant heterogeneity, I show that active hate groups are more likely to be present when the percent of households below the poverty line increases. Attempting to reduce the impact of poverty through welfare payments does not, however, appear to reduce the likelihood a hate group is present. In fact, it appears to increases it. In addition, counties that increase real per capita spending on transportation are associated with a lower probability that an active hate group is present.

Hate groups share many characteristics with social clubs. Members must sacrifice private consumption to be eligible for goods and services produced by the club. Part II discusses past research on the general dynamics of group formation and on hate groups and hate crime. Part III discusses possible reasons why individuals join hate groups. Part IV presents general facts about the number of hate groups across the counties of the United States. Part V discusses the fixed effects logistic estimation methodology in more detail. The estimation results are introduced and discussed in Part VI. Conclusions and possible extensions are presented in Part VII.

\section{Past Research}

In the 1940s, psychologists and sociologists sought and found links between macroeconomic conditions, such as the price of cotton and the unemployment rate, and the number of lynchings in the south (Hovland and Sears, 1940). ${ }^{3}$ Recently, sociologists have reexamined these data using robust statistical techniques and extending the time frame and find no relationship between economic conditions and the number of racially motivated lynchings (Green, Glaser, and Rich, 1998). Searching for the sources of racial and ethic prejudices, sociologists have found a link between demographics and demographic change and racial harassment (Green, Strolovitch, and Wong, 1998).

Economists initially entered this arena by analyzing why certain goods are provided through clubs instead of private markets (Buchanan, 1965 and Cornes and Sandler, 1986). The results of these inquiries generated rational choice models of group formation. As research evolved, economists began to incor-

\footnotetext{
${ }^{3}$ For a detailed survey on the sociology of social interactions see Weber (1978).
} 
porate the impact that social setting or interactions can have on individual decisions. Iannaccone (1992) and Berman (2000 and 2003) demonstrate why rational, utility maximizing individuals voluntarily sacrifice to join religious organizations, fraternities and sororities, communes, and political parties.

Religious prohibitions discussed in Iannaccone (1992) come in many forms: Christian Scientists refuse medical care; Jehovah Witnesses do not celebrate birthdays or vote; and Orthodox-Jewish males do not shake women's hands. Membership prohibitions also occur in various non-religious groups, including hate groups: skinheads, by definition, have shaved heads; during sorority rush members are not allowed talk with incoming freshmen; and in the gang world the rival Crips and Bloods gangs do not use the first letter in the other group's name, so Crips will not speak the letter "B"; Bloods will not use the letter "C" and will replace it with a "B".4 The participation in such prohibitions reveals to other members that the individual is committed to the organization, and as such, grants an active member certain privileges and benefits. Joining reveals that these benefits of membership are greater than the cost associated with signalling commitment to the group.

Looking at hate groups directly, Jefferson and Pryor (1999) use SPLC data on hate groups in 1997 to analyze whether economic or sociological explanations can explain the existence of a hate group in a county. Because these data are reported at the group level, and not the individual level, they attempt to consider factors that might influence the level of intolerance in a community. Relying on cross-sectional variation, they proxy the influence of history and geography, government interference, frustration, status anxiety, and social disintegration on the whether a hate group is present in a county. Using a dichotomous dependent variable, they classify counties as either having or not having a hate group present as sign of intolerance. Their results suggest that counties that are part of an MSA and within a state that was a member of the Confederate States of America are more likely to be home to an active hate group. They conclude that economic and sociological explanations "are far less important than adventitious circumstances due to history and particular condition." This final conclusion gives communities little in the way of suggestions on how local governments might alter policy to reduce hate group activity.

Jefferson and Pryor's logistic estimates do report "coefficients [that] are statistically significant, but with the "wrong' sign." For instance, they find that a one percent increase in the local property tax per capita in 1987 lowers the probability a hate group is present in 1997 by 3.5 percent. Thus their results suggest that, in the cross-section, a county with higher property taxes per capita is associated with fewer hate groups. This 'wrong' property tax result suggests three possibilities a) that local communities with greater tolerance also have higher property taxes, b) that the relationship is spurious, or c) that local communities with higher property taxes also fund programs that

\footnotetext{
${ }^{4}$ So instead of using the word cigar they will say "bigar.
} 
improve the level of tolerance or at least reduces the benefit of hate group activity. More importantly this raises the possibility that local communities may not be hamstrung by historical condition. Policymakers may be able to alter the level of hate group activity within their local communities by altering their local tax policy.

\section{Reasons For Hate Group Formation}

Often cited reasons for hate group formation include peer validation, frustration, scapegoating, and boredom. Groups form when a small number of like-minded individuals believe they have been wronged in a similar manner and are searching for ways to right perceived wrongs. Group formation provides its members a sense of belonging, security, and empowerment.

One hypothesis put forth by McDevitt (1993) in Hate Crimes: The Rising Tide of Bigotry and Bloodshed, is that the impetus for organizing is often based on turf issues (McDevitt, 1993). Much like those found by Green, Strolovitch, and Wong (1998), McDevitt uses Boston data and observes that many of these crimes involved violence directed at dissimilar others moving into a previously segregated area. Changes in demographics may be an important component of hate group formation, but this conclusion leaves local governments little guidance on how they might craft policy to reduce such conflicts.

Individuals commonly cite the thrill associated with the victimization (Levin, 1993). By forming a group, these individuals validate themselves by "committing an act that enhances one's image internally, with a peer group, and with society at large" (Levin, 1993). In this sense, hate groups are much like gangs. In his work on gangs, Klein summarizes the psychological factors in his statement that "the gang is seen as an aggregate of individuals held together more by their own shared incapacities than by mutual goals. Primarily, group identification is important as it serves individual needs; it leads to delinquent group activity only secondarily and only in the absence of pro-social alternatives" (Klein, 1995).

Though often established for ideological reasons, membership may also serve as a social safety net. The benefit of this security network is threefold: protection from violence imposed by other groups; transfers of resources in time of need; and a source of employment for those with limited skills. A hate group that is able to insure its members safety and financial security, or at least financial support through unemployment spells, will have more active members willing to sacrifice in order to stay on good terms with their fellow members. If a member faces financial difficulty, he or she may first turn to their fellow members for assistance before seeking local government assistance. However, if the benefits provided by the local government are large enough, or if law enforcement is able to maintain a high level of safety, or the local governments development efforts increase the number of job opportunities, then even those individuals who may consider joining a hate group in response to a feeling of being wronged, may find alternative ways to overcome their 
challenges.

For example, schooling is both a function of quality and content. Parents, whom disagree with much of the public school content, may not remove their child if they believe the overall quality is sufficiently high. However, as public school quality declines, the net benefit of removing their child increases. ${ }^{5}$ This is especially true for parents who believe the content is inappropriate. Thus, these families do not interact with those whom hold various views and these biased views of the parents are more likely to be maintained and passed on. Disagreeing with many public school teachings, most neo-Nazis and many Christian Identity members choose to home school their children or send their children to private schools. ${ }^{6}$ Therefore, ceteris paribus, as the quality of public schools increases, the likelihood that these biased views are maintained declines.

Government programs, such as welfare, can theoretically serve to enhance the net benefit of joining an active hate groups. Hate group membership often requires certain prohibitions and costly signals, such as tattoos, piercings, and the like, that reduce labor market opportunities. Fewer labor market options manifest themselves through lower wages and possibly through reduced access to non-government assistance. Government supplied goods and services may serve to sustain active hate groups by reducing the net negative impact membership may have on labor market income. For instance, government medical assistance may serve to offset the negative effect a costly signal may have on a members access to employers that provide health insurance.

\section{General Facts About Hate Groups}

The Southern Poverty Law Center tracks hate groups by "using hate group publications and websites, citizen and law enforcement reports, field sources and news reports" (Southern Poverty Law Center). Initiated in 1981, 1997 marks the first year the SPLC attempted to gather data for all known active hate group chapters by city. ${ }^{7}$ Although the SPLC now tracks many types of organizations only $\mathrm{Ku}$ Klux Klan, neo-Nazi, racist skinhead, and Christian

\footnotetext{
${ }^{5}$ Hoxby 1998 shows that as per pupil school spending decreases, drop out rates increase. Accounting for both the possible endogeneity of private enrollment and public expenditures - switching endogeneity - as well as possible Tiebout sorting, Goldhaber (1999) finds that increases in public school expenditure per pupil significantly reduces private school enrollment.

${ }^{6}$ In 1999, before the Aryan Nations lost their Idaho compound, Salon writer and associate editor, Amy Benfer, discussed her daughter's public schooling experience with one of the Neo-Nazi women: "They taught her that the Indians saved the Pilgrims' lives," Christian [a neo-Nazi mother] says. Then came Black History Month, when the children learned about Martin Luther King Jr. Says Christian: "My daughter is not black. My daughter has no need to know about a black activist."

${ }^{7}$ Although the Southern Poverty Law Center reports hate group location by city or town, the analysis is performed at the county level for both theoretical and empirical reasons: First, many hate groups chapters hold rallies and recruitment meetings outside their home towns in locations nearby and thus have members from the surrounding towns and townships.
} 
Identity groups are available for every year from 1997 to $2007 .^{8}$ Between 1997 and 2007, 793 US counties, or approximately 25 percent, were home to at least one active hate group. ${ }^{9}$ Figure 3 shows the maximum number of $\mathrm{Ku}$ Klux Klan, neo-Nazi, Racist Skinheads, and Christian Identity chapters by county reported during any calendar year from 1997 to 2007. From 1997 to 2007, Harris County, Texas, with seven chapters in 2006, and Cook County, Illinois, with seven chapters in 1997, 2005, and 2006, were home to the largest number of active hate group chapters during a single calendar year. Counties located in states that were part of the Confederate States of America (CSA) are well represented and make up 43.4 percent of those reporting an active hate group throughout the period. However, over half of the counties reporting an active hate group were located outside the former CSA. In fact, of the twelve counties that report five or more active hate group chapters during a calendar year, only three: Harris, Texas in 2006 and 2007; Tarrant, Texas in 1998, and Spartanburg, South Carolina in 2005 and 2006 are located in states that were part of the CSA.

Figure 4 depicts the change in the number of active Ku Klux Klan, neoNazi, Racist Skinheads, and Christian Identity chapters present in 2007 compared to those active in 1997. Forty-one states are home to counties that experienced either an increase or decrease in the number of active hate group chapters. This suggests that, while history may be important, other more recent factors may also play a role in hate group activity. Ocean, New Jersey and Harris, Texas experienced the largest increase in the number of active hate groups with an increase of five. Four other counties: Dallas, Texas; Maricopa, Arizona; Davidson, Tennessee; and Forrest, Mississippi each witnessed an increase of three hate group chapters. According to the SPLC data, the two counties that had the greatest reduction in the number of active hate groups, San Diego County, California and Los Angeles County, California were home to four fewer hate groups in 2007 relative to the initial year of collection in 1997.

Although similar, hate groups are by no means identical. Each organization, as shown in Table 1, has different levels of prohibitions and goals. Over the ten years observed, 8.3 percent of the county-year observations report the presence of at least one active Ku Klux Klan, neo-Nazi, Racist Skinhead, or Christian Identity chapter, while 99 percent of counties reported no active

Second, because many of these towns are non-Metropolitan Statistical Areas, county level data represents the least aggregated measures of crime, schooling, unemployment, and the like that are available.

${ }^{8}$ In 2000 the Southern Poverty Law Center began monitoring Neo-Confederate organizations. This study does not include those organizations because of their initial omission by the Southern Poverty Law Center, nor does it include Black Separatists.

${ }^{9}$ Not all active hate groups can be assigned to a single county. For instance the SPLC reports an active chapter of the Knights of the White Kamellia (KKK) is present in NC, but does on list a city. When no city is reported, the hate group is not included in the analysis. The portion of active groups not included ranges from 1.2 percent in 1998 to 12.8 percent in 2007. 
hate group for at least one year. Counties reporting no active hate group for at least one year did so about 92 percent of the time. Counties reporting an active hate group for at least one year, were home to an active hate group about 33 percent of the time.

Looking at the individual hate group types, 3.8 percent of the county-year observations report the presence of at least one active Ku Klux Klan chapter. Counties reporting no KKK chapters for at least one year did so about 96 percent of the time. Counties reporting an active KKK chapter for at least one year, were home to an active KKK chapter about 26 percent of the time. Neo-Nazi chapters look similar to KKK chapters with 4.1 percent of countyyear observations reporting the presence of a Neo-Nazi chapter. Only about 2 percent of counties were home to a Neo-Nazi organization over the ten year period. Because skinheads are much more transient than most other type of hate groups, counties that were home to a Neo-Nazi chapter reported an active chapter only 15 percent of the time. Christian Identity Churches were present in 3.5 percent of the counties. Christian Identity Churches were the least likely to disband. Counties that were home to a Christian Identity Church for at least one year, were home to an active church thirty-four percent of time.

\section{Estimation Method}

While anecdotal evidence suggests that the number of chapters is positively correlated with the number of members, the SPLC does not report the number of members per chapter. ${ }^{10}$ Therefore, changes in the number of chapters may be a poor measure of the level of activity. The formation of additional active hate group chapters from one year to the next may simply be a result of the splintering of one large group. The reduction in the number of groups may simply be the result of a merger. Following Jefferson and Pryor (1999), this analysis will focus on whether a county is home to any active hate group chapter and not the total number of active hate group chapters. In addition, because the SPLC uses "group publications and websites, citizen and law enforcement reports, field sources and news reports," it is possible that a county is home to a hate group even though it is not reported as present for that calendar year. Therefore, using year to year variation may result in false negatives. ${ }^{11}$ Furthermore, changes in government policy take time to affect individuals choices and behavior so that annual estimations using one year lags may not capture the medium run effects of changes in government policy on hate group activity.

To address these issues, I first construct a dichotomous variable:

\footnotetext{
${ }^{10}$ For two discussions on the correlation between number of active chapters and membership see: "The Year in Hate: As many hate groups consolidate and others mainstream their message, a new kind of extremism is taking shape." in Intelligence Report (Winter 2000) and The Stephen Roth Institute For The Study of Contemparary Antisemitism and Racism Annual Report United States 2004.

${ }^{11} \mathrm{An}$ anonymous referee is responsible for this helpful suggestion.
} 


$$
y_{i, t}=\left\{\begin{array}{c}
1 \text { if number of active hate group chapters is }>0 \\
0 \text { if no active hate group chapters present }
\end{array}\right\}
$$

where $y_{i, t}$ equals one if an active hate group chapter is present in county $i$ at time $t$ and zero if no active hate group chapter is reported.

I then estimate the effects of economic and social stability, demographics, and county government taxation and expenditures on the probability any hate group chapter is active in a county using the following equation:

$$
y_{i, t}=\left\{\begin{array}{lc}
1 \text { if } & x_{i, t-l a g} \beta+\alpha_{i}+\eta_{t}+\varepsilon_{i t} \geq 0 \\
0 & \text { otherwise }
\end{array}\right\}
$$

where $y_{i t}$ is the presence of an active hate group, $x_{i, t-l a g}$ is the vector of explanatory variables for county $i$ in time period $t-l a g$, and $\beta$ is the vector of parameters to be estimated. The time-invariant, individual county specific effect represented by $\alpha_{i}$ can be interpreted as the unobserved heterogeneity explanatory variable that controls for omitted variables that differ between counties but are constant over time and $\varepsilon_{i, t}$ is assumed to be logistically distributed and independent of $\left(x_{i, t-l a g}, \alpha_{i}\right) .{ }^{12}$ Including the year dummies, $\eta_{t}$, controls for omitted national changes over time that affect all counties similarly. Using this fixed effects, or conditional, logistic estimation methodology uses within county variation to determine if a change in local government policies is associated with a changes in hate group activity within that county.

Although this method reduces the variation in the measured magnitude of hate group activity, it focuses on the whether any hate group members were active and eliminates any errors associated with measuring the level of activity. Furthermore, to reduce the possibility of drawing erroneous conclusions from false negatives when using year to year values, the the logistic estimation only looks at the presence of hate group every five years. If a county is still home to an active hate group after five years, the likelihood of a false positive is unlikely. Conversely, if a county does not report an active hate group at either ends of the five year interval, the probability that this results from a false negative is also quite small. In addition using five year intervals eliminates the possibility of first-order autocorrelation.

Although local governments may have little control over long term economic stability, demographic changes, and "circumstances due to history and particular condition," local government officials may be able to alter policies so as to reduce the net benefit of starting or joining such an organization. Behavioral changes due to government policy often take time to filter through the economy. Individuals must first realize and understand the policy change. Then, they must alter their behavior according to the new government policies. By lagging government policy variables by ten years, the estimation is

\footnotetext{
${ }^{12}$ Assuming that hate groups did not alter their voting behavior over this time period, using fixed effects partially addresses any worry that that hate groups "may vote for policies that reduce the local government provision of services (Glaeser 2005)."
} 
more likely to capture any medium run effects these policies may have on hate group activity within a county. ${ }^{13}$

Following Honore (2002), with $T=2$ and in the case for $d_{t=2002}$ and $d_{t=2007}$ equal to either 0 or 1 , the estimator used in this analysis is:

$$
\begin{gathered}
P\left(y_{i, 2002}=d_{2002}, y_{i, 2007}=d_{2007} \mid x_{i, 2002-\text { lag }}, x_{i, 2007-\text { lag }}, \alpha_{i}\right) \\
=\frac{\exp \left(x_{i, 2002-\text { lag }} \beta+\alpha_{i}\right)^{d_{2002}}}{1+\exp \left(x_{i, 2002-\text { lag }} \beta+\alpha_{i}\right)} \frac{\exp \left(x_{i, 2007-\text { lag }} \beta+\alpha_{i}\right)^{d_{2007}}}{1+\exp \left(x_{i, 2007-\text { lag }} \beta+\alpha_{i}\right)}
\end{gathered}
$$

Reducing this equation reveals that a fixed effect estimator does not rely on $\alpha_{i}$,

$$
\begin{gathered}
P\left(y_{i, 2002}=d \mid x_{i, 2002-\text { lag }}, x_{i, 2007-\text { lag }}, \alpha_{i}, y_{i, 2002}+y_{i, 2007}=1\right) \\
=\frac{\exp \left(\left(x_{i, 2002-\text { lag }}-x_{i, 2007-\text { lag }}\right) \beta\right)^{d}}{1+\exp \left(\left(x_{i, 2002-\text { lag }}-x_{i, 2007-\text { lag }}\right) \beta\right)}
\end{gathered}
$$

for $d$ equal to either zero or one. Because the estimator considers counties where $y_{i, 2002}+y_{i, 2007}=1$, this method only considers counties that switch from being home to an active hate group to not or vice versa. ${ }^{14}$ As stated by Honore, 2002 "[i]t is intuitively appealing that the individuals who do not switch, are not used to estimate $\beta$, those [counties] can be rationalized either by extremely large or by extremely small values of $\alpha_{i}$." Counties that are always home to an active hate group, and thus report all ones, or are never home to an active hate group, and thus report all zeros for 2002 and 2007 are dropped.

Table 2 displays the summary statistics for each explanatory variable. In order to account for local levels of economic and social stability, the $x_{i, t-l a g}$ vector includes the crime index, real median household income, the unemployment rate, and the poverty rate at the county level. Because levels and changes in demographic heterogeneity are often associated with increases in social tensions, I include sex and age measures, the percentage of blacks and Hispanics, and the population density. Each of these stability and demographic measures are lagged two years. Finally to determine the affects of local government policies, I include the real per capita property taxes and expenditures on education, welfare, healthcare/hospital services, police, fire, corrections, highway/transportation, and community development. Because local government

\footnotetext{
${ }^{13}$ Lagging the taxes and expenditures by ten years follows Jefferson and Pryor (1999) methodology.

${ }^{14}$ Because 1997 was the first year the SPLC attempted to collect data on all known hate groups, the SPLC's methodology may still have been in its infancy. The SPLC may have found fewer groups in 1997 simply because they were learning how to locate these various types of organizations. Therefore, comparing the growth from 1997 to any following year may simply be due to improved methodology and not an actual increase in the number of existing groups. To avoid this possibility, I chose to analyze hate group activity a) a few years after their initial collection of 1997 so that much of the initial learning process had occurred and b) for years when the Census of Governments, reported every five years on the $2 \mathrm{~s}$ and $7 \mathrm{~s}$, is available.
} 
policy changes often take time to filter throughout the locality, each measure of local property taxes and expenditures are lagged ten years.

Fixed effects estimation relies on within county variation, or stated less generally, counties that realize a change in hate group activity. Figure 5 maps the location of these counties that realized a change in presence of hate group activity from 2002 to 2007. In 2002, 286 counties were home to an active KKK, Neo-nazi, skinhead, or Christian Identity chapter. Shown in blue, 168 counties, or about 58.7 percent of those reporting an active hate group in 2002, were no longer home to any active hate groups by 2007. One hundred and eighteen counties were home to active hate groups in both 2002 and 2007. By 2007, 263 counties reported an active KKK, Neo-nazi, skinhead, or Christian Identity chapter and included 145 "red" counties that had reported no active hate groups in 2002. For both 2002 and 2007, 2712 counties were never home to an active hate group.

\section{Estimation Results}

The results of the Hausman test supporting the use of fixed effects is reported in Table 3. The Hausman test reveals that the random effects estimator, although more efficient, violates one or more assumptions and returns estimators significantly different from the fixed effects estimation. Therefore the results of the fixed effects logistic estimation are reported in Table 4. The results report clustered standard errors in order to account for non-random errors within each panel (Rogers, 1993; Williams, 2000; and Wooldridge, 2002).

Controlling for unobserved heterogeneity across counties results in an impricisely estimated effect of a change in per capita property taxes. This result differs from the negative cross-sectional relationship found by Jefferson and Pryor (1999). So although higher property taxes are associated with less hate group activity, raising the local property tax is not associated with a change in the likelihood that an active hate group is present.

Reinforcing Green, Glaser, and Rich (1998), the results show no relationship between the unemployment rate and median income and the presence of an active hate group. However, economic welfare, measured by the poverty rate tells a slightly different story. A one percentage point increase in the poverty rate, or an increase of about one fifth of the standard deviation, is associated with a 17.5 percent increase in the probability that an active hate group is present. ${ }^{15}$ Those witnessing an increase in poverty are likely to seek out reasons for their welfare loss. Looking for a scapegoat, individuals may be attracted to organizations that are more extreme, including hate groups. These results conflict with the individual level analysis of Hezbollah by Kreuger and Maleckova (2002). Their research found a positive relationship between living above the poverty line or exposure to secondary education and participation

\footnotetext{
${ }^{15}$ Though the marginal effects would reveal additional information, they are not available for the fixed effect model because individual effects, which are needed to calculate the marginal effect, are not consistently estimated with fixed effects logit (Wooldridge, 2002).
} 
in Hezbollah and that Israeli Jews who attack Palestinians are "overwhelmingly from high-paying occupations. The difference may lie in the level of estimation. However, it may also point to a difference between domestic hate groups and international organizations such as Hezbollah. Hate groups in the United States may have fewer resources to carry out their plans and thus are poorer than their international likeness. More research is needed to determine differences between these domestic and international organizations.

Attempting to reduce the impact of poverty through welfare payments does not, however, appear to be associated with a reduction in hate group activity. In fact, the reverse is true. A one dollar increase in welfare spending per capita is associated with a 0.4 percent increase in the probability that a hate group is present. By granting a greater amount of welfare payments, policymakers may reduce the net costs of signaling membership. More over, for groups that are more mobile, like racist skinheads and neo-Nazis, these higher welfare benefits may actually attract these individuals to local communities that provide greater welfare benefits. Unfortunately, policymakers searching for ways to help those in need, while at the same time seeking ways to reduce hate group activity, may need to look for other ways to improve the lives of those at or below the poverty line.

Transportation expenditures also appear correlated with reductions in hate group activity. A one dollar per capita increase in transportation expenditures is associated with a 0.7 percent reduction in the probability that a hate group is present. Though further research is needed, one possibility is that funding public transportation may provide a public good that lowers the cost of daily commutes from areas with few job opportunties to areas with greater job opportunity. Greater provision of public transportation may reduce the costs of searching for a job and switching jobs. Other measures of government policy included do not appear to affect the presence of active hate groups.

Although race is not associated with hate group activity, the percent of a county that is female between the ages of 5 and 14 is positively correlated with the likelihood that a hate group is present. A one percentage point increase in the portion of a county's female population between 5 and 14 is almost 4 times more likely to be home to an active hate group. While an increase in males age 5 to 14 reduces the probability an active hate group is present.

\section{Conclusion}

Although economic and sociological explanations may be less important than history or particular condition, government officals may be able to craft policies that reduce hate group activity. Local and state policymakers looking for a fiscal tool to reduce the presence of active hate groups may wish to look toward polices that target poverty and transportation. Unfortunately, the results suggest that enhanced welfare payments that lower the burden of those below the poverty line may exacerbate the problem of hate group activity. Welfare payments may serve to reduce the net loss in labor income that may 
be associated with hate group membership. However, it may also be the case that poverty and welfare payments may be capturing some other omitted factor not controlled for in the logistic estimates. These results also differ from those found by Kreuger and Maleckova (2002) and may speak to subtitle differences between domestic hate groups and international organizations.

There are many other possible methods for counties to reduce the incentives to create and join hate groups. Various policies that focus directly on hate group activities may further reduce their presence. Further research is needed in this area if we are to reduce or eliminate the desire of individuals to express their frustrations through organizations that are built on extreme ideological grounds.

\section{References}

[1] Anti Defamation League Website. Retrieved February 4, 2005. http://www.adl.org/.

[2] Buchanan, James. (1965). "An Economic Theory of Clubs". Economica, $32,1-14$.

[3] Cornes, Richard and Sandler, Todd. (1986). The Theory of Externalities, Public Goods and Club Goods. (New York: Cambridge University Press).

[4] Berman, Eli. (2000). "Sect, Subsidy, and Sacrifice: An Economist's View of Ultra-Orthodox Jews," Quarterly Journal of Economics. 115, (3), 905953.

[5] Berman, Eli. (2003). "Hamas, Taliban, and the Jewish Underground: An Economist's View of Radical Religious Militias." National Bureau of Economic Research Working Paper. No. 10004.

[6] Goldhaber, Dan. (1999)."An Endogenous Model of Public School Expenditures and Private School Enrollment." Journal of Urban Economics, 46: 106-128.

[7] Glaeser, Edward L. (2005). "The Political Economy of Hatred," Quarterly Journal of Economics. 120 (1), 45-86.

[8] Green, Donald P., Strolovitch, Dara Z., and Wong, Janelle S. (1998). "Defended Neighborhoods, Integration, and Racially-Motivated Crime." American Journal of Sociology. 104, 372-403.

[9] Green, Donald P., Glaser, Jack, and Rich, Andrew, (1998). "From Lynching to Gay-Bashing: The Elusive Connection Between Economic Conditions and Hate Crime." Journal of Personality and Social Psychology, 75, 82-92.

[10] Hoffer, Eric. (1989). The True Believer: Thoughts on the Nature of Mass Movements (New York, NY: Harper and Row).

[11] Honoré, B. (2002): "Nonlinear Models with Panel Data", Portuguese Economic Journal, 1, 163-179.

[12] Hovland, C. I., and Sears, R. R. (1940). "Minor Studies of Aggresion: VI. Correlation of Lynching with Economic Indicies." The Journal of Psychology, 9, 301-310. 
[13] Iannaccone, Laurence R. (1992). "Sacrifice and Stigma: Reducing Freeriding in Cults, Communes, and Other Collectives," Journal of Political Economy, 100 (2), 271-291.

[14] Hoxby, Caroline M. "How Much Does School Spending Depend On Family Income? The Historical Origins Of The Current School Finance Dilemma," (1998). American Economic Review, v88(2,May), 309-314.

[15] Jefferson, Philip N, and Pryor, Frederic L. (1999). "On the Geography of Hate," Economics Letters, 65, (3), 389-395.

[16] Kleg, Milton. (1993). Hate Prejudice and Racism. (The State of New York: Albany Press).

[17] Klein, M. W. (1995). The American street gang: Its nature, prevalence and control. New York: Oxford University Press Inc.

[18] Krueger, Alan B. and Maleckova, Jitka, (2002). "Education, Poverty, and Terrorism: Is There a Causal Connection?", Journal of Economic Perspectives, vol. 17, no. 4, Fall 2003, pp. 119-44

[19] Levin, Brian. (1993) "A Dream Deferred: the Social and Legal Implications of Hate Crimes in the 1990s". The Journal of Intergroup Relations, vol. xx, no. 3, Fall.

[20] McDevitt, Jack. And Jack Levin.(1993) "Hate Crimes: The Rising Tide of Bigotry and Bloodshed". 9-19.

[21] Rogers, W. H. 1993. Regression standard errors in clustered samples. Stata Technical Bulletin 13: 19-23. Reprinted in Stata Technical Bulletin Reprints, vol. 3, 88-94.

[22] Salon Online Magazine. http://www.salon.com/mwt/hot/1999/07/08/ skinhead/index.html, viewed 1/12/05.

[23] Southern Poverty Law Center Website: http://www.splcenter.org/. (Retrieved 07/18/08).

[24] The Southern Poverty Law Center. (1998). "474 Hate Groups Blanket America." Intelligence Report. Issue 89.

[25] The Southern Poverty Law Center. (1999). "Hate Groups Top 500." Intelligence Report. Issue 93.

[26] The Southern Poverty Law Center. (2000). "The Decade in Review." Intelligence Report. Issue 97.

[27] The Southern Poverty Law Center.(2001). "Blood on the Border." Intelligence Report. Issue 101.

[28] The Southern Poverty Law Center. (2002). "The Year in Hate." Intelligence Report. Issue 105.

[29] The Southern Poverty Law Center. (2003). "Hate Takes a Hit." Intelligence Report. Issue 109.

[30] The Southern Poverty Law Center. (2004). "Age of Rage." Intelligence Report. Issue 114.

[31] The Southern Poverty Law Center.(2005). "Holy War". Intelligence Report. Issue 117.

[32] The Southern Poverty Law Center.(2006). "The Year in Hate". Intelligence Report. Issue 121. 
[33] The Southern Poverty Law Center. (2007). "The Year in Hate". Intelligence Report. Issue 125.

[34] The Southern Poverty Law Center. (2008). "The Year in Hate". Intelligence Report. Issue 129.

[35] The Stephen Roth Institute. 2004. For The Study of Contemparary Antisemitism and Racism Annual Report United States 2004.

[36] United States Census. 1992 Census of Government. Volume 4. Government Finances. Number 5, Compendium of Government Finances

[37] United States Census. 1997 Census of Government. Volume 4. Government Finances. Compendium of Government Finances.

[38] Weber, Max, (1978). Economics and Society. (Berkeley, California: University of California Press).

[39] Williams, R. L. 2000. A note on robust variance estimation for clustercorrelated data. Biometrics 56: 645-646.

[40] Wooldridge, J. M. 2002. Econometric Analysis of Cross Section and Panel Data. Cambridge, MA: MIT Press.

\section{A Data Appendix}

crime comes from the Uniform Crime Reports County Data. 1997-2005 Retrieved [June 20, 2006], from the University of Virginia, Geospatial and Statistical Data Center: http://fisher.lib.virginia.edu/collections/stats/crime/.

income is the median household income in thousands (\$1000s) of 2006 dollars by county as reported by the U.S. Census Bureau, "State and County Income and Poverty Estimates (SAIPE) from 1997 through 2005. http:// www.census.gov/hhes/www/saipe/county.html. Viewed (07/10/08).

unemployment rate is the annual average percent of county residents who are unemployed and looking for a job as reported by the United States Department of Labor: Bureau of Labor Statistics. Labor Force Data by County, Annual Averages (Viewed (07/10/08):

ftp://ftp.bls.gov/pub/special.requests/la/laucnty97.txt

ftp://ftp.bls.gov/pub/special.requests/la/laucnty98.txt

ftp://ftp.bls.gov/pub/special.requests/la/laucnty99.txt

ftp://ftp.bls.gov/pub/special.requests/la/laucnty00.txt

ftp://ftp.bls.gov/pub/special.requests/la/laucnty01.txt

ftp://ftp.bls.gov/pub/special.requests/la/laucnty02.txt

ftp://ftp.bls.gov/pub/special.requests/la/laucnty03.txt

ftp://ftp.bls.gov/pub/special.requests/la/laucnty04.txt

ftp://ftp.bls.gov/pub/special.requests/la/laucnty05.txt

poverty is the portion of a county?s residents that are below a household income threshold as reported by the U.S. Census Bureau, "State and County Income and Poverty Estimates (SAIPE) from 1997 through 2005. http:// www.census.gov/hhes/www/saipe/county.html. Viewed (07/10/08).

adult male is the percentage of the county population that is male and between the ages of 15 and 44. U.S. Census Bureau, Population Division: 
County estimates by demographic characteristics - age, sex, race, and Hispanic Origin. http://www.census.gov/popest/datasets.html (Viewed 7/15/08) U.S. Census Bureau, Population Division:

adult female is the percentage of the county population that is female and between the ages of 15 and 44. U.S. Census Bureau, Population Division: County estimates by demographic characteristics - age, sex, race, and Hispanic Origin. http://www.census.gov/popest/datasets.html (Viewed 7/15/08)

male youth is the percentage of the county population that is male and between the ages of 5 to $14(1997-1999)$ or 5 to 13 (2000 - 2005) U.S. Census Bureau, Population Division: County estimates by demographic characteristics age, sex, race, and Hispanic Origin. http:// www.census.gov/popest/datasets.html (Viewed 7/15/08)

female youth is the percentage of the county population that is female and between the ages of 5 to 14 (1997 - 1999) or 5 to 13 (2000 - 2005). U.S. Census Bureau, Population Division: County estimates by demographic characteristics - age, sex, race, and Hispanic Origin. http:// www.census.gov/popest/datasets.html (Viewed 7/15/08)

black is the percentage of county population that is black. U.S. Census Bureau, Population Division: County estimates by demographic characteristics age, sex, race, and Hispanic Origin. http:// www.census.gov/popest/datasets.html (Viewed 7/15/08)

hispanic is the percentage of the county population that is Hispanic. U.S. Census Bureau, Population Division: County estimates by demographic characteristics - age, sex, race, and Hispanic Origin. http:// www.census.gov/popest/datasets.html (Viewed 7/15/08)

msa is the Metropolitan Statistical Area reported by the Population Division, U.S. Census Bureau in 1999 and updated in 2003: http:// www.census.gov/population/estimat city/99mfips.txt (Viewed 1/29/2007).

population density is calculated from the county population in U.S. Census Bureau, Population Division: County estimates by demographic characteristics - age, sex, race, and Hispanic Origin, (Viewed 7/15/08) divided by the land area in square miles from the U.S. Census Bureau (Viewed 1/29/2007).

hate group total is the total number of hate group chapters active in a county. This variable is the sum of all Ku Klux Klan, Neo-Nazi, Racist Skinheads, and Christian Identity Chapters active at the county level. These data are reported annually at the city level by the Southern Poverty Law Center in their quarterly publication the Intelligence Report. Each annual report reports activity for the previous year.

- 1998. "474 Hate Groups Blanket America." The Southern Poverty Law Center. Issue 89.

- 1999. "Hate Groups Top 500." The Southern Poverty Law Center. Issue 93.

- 2000. "The Decade in Review." The Southern Poverty Law Center. Issue 97. 
- 2001. "Blood on the Border." The Southern Poverty Law Center. Issue 101

- 2002. "The Year in Hate." The Southern Poverty Law Center. Issue 105.

- 2003. "Hate Takes a Hit." The Southern Poverty Law Center. Issue 109.

- 2004. "Age of Rage." The Southern Poverty Law Center. Issue 114.

- 2005. "Holy War". The Southern Poverty Law Center. Issue 117

- 2006. "The Year in Hate". The Southern Poverty Law Center. Issue 121.

- 2007. "The Year in Hate". The Southern Poverty Law Center. Issue 125.

- 2008. "The Year in Hate". The Southern Poverty Law Center. Issue 129.

kkk is the total number of Ku Klux Klan Chapters active in a county. These data are reported annually at the city level by the Southern Poverty Law Center in their quarterly publication the Intelligence Report, Issues 85, 89, 93, 97, 101, 105, 109, 114, 117, 121, 125, 129.

nazi is the number of Neo-Nazi chapters active in county. These data are reported annually at the city level by the Southern Poverty Law Center in their quarterly publication the Intelligence Report, Issues 85, 89, 93, 97, 101, 105, 109, 114, 117, 121, 125, 129.

skinheads is the number of racists skinhead chapters active in a county. These data are reported annually at the city level by the Southern Poverty Law Center in their quarterly publication the Intelligence Report, Issues 85, 89, 93, 97, 101, 105, 109, 114, 117, 121, 125, 129.

identity is the number of Christian Identity Churches active in a county .These data are reported annually at the city level by the Southern Poverty Law Center in their quarterly publication the Intelligence Report, Issues 85, 89, 93, 97, 101, 105, 109, 114, 117, 121, 125, 129.

consumer price index is from the United States Department of Labor: Bureau of Labor Statistics: Consumer Price Index. Washington, D.C. ftp:// ftp.bls.gov/pub/special.requests/cpi/cpiai.txt (viewed 7/10/08)

property tax are "taxes conditioned on ownership of property and measured by its value. Includes general property taxes related to property as a whole, real and personal, tangible or intangible, whether taxed at a single rate or at classified rates, and taxes on selected types of property, such as motor vehicles, or on certain or all intangibles. These measures come from the United States Census. Census of Government. Volume 4. Government Finances. Number 5, Compendium of Government Finances.

education expenditures includes "schools, colleges, and other educational institutions (e.g., for blind, deaf, and other handicapped individuals), and educational programs for adults, veterans, and other special classes. These measures come from the United States Census. Census of Government. Volume 4. Government Finances. Number 5, Compendium of Government Finances.

library expenditures are "provision and support of public library facilities and services. These measures come from the United States Census. Census of Government. Volume 4. Government Finances. Number 5, Compendium of Government Finances. 
welfare expenditures "includes institutional and noninstitutional assistance to the needy, plus the administration of such assistance." These measures come from the United States Census. Census of Government. Volume 4. Government Finances. Number 5, Compendium of Government Finances.

hospital expenditures consists of "financing, construction acquisition, maintenance or operation of hospital facilities, provision of hospital care, and support of public or private hospitals." These measures come from the United States Census. Census of Government. Volume 4. Government Finances. Number 5, Compendium of Government Finances.

health expenditures includes "outpatient health services, other than hospital care, including: public health administration; research and education; categorical health programs; treatment and immunization clinics; nursing; environmental health activities such as air and water pollution control; ambulance service if provided separately from fire protection services, and other general public health activities such as mosquito abatement. School health services provided by health agencies (rather than school agencies) and included here." These measures come from the United States Census. Census of Government. Volume 4. Government Finances. Number 5, Compendium of Government Finances.

highway expenditures include "construction, maintenance, and operation of highways, streets, and related structures, including toll highways, bridges, tunnels, ferries, street lighting and snow and ice removal. However, highway policing and traffic control are classed under Police Protection." These measures come from the United States Census. Census of Government. Volume 4. Government Finances. Number 5, Compendium of Government Finances.

transportation expenditures "comprises the functions of Highways, Air Transportation, Parking Facilities, Water Transport and Terminals, and Transit Subsidies." These measures come from the United States Census. Census of Government. Volume 4. Government Finances. Number 5, Compendium of Government Finances.

police expenditures consists of "[l] ocal government payments for police and traffic safety activities amount to the most significant part of police protection." These measures come from the United States Census. Census of Government. Volume 4. Government Finances. Number 5, Compendium of Government Finances.

fire expenditures includes "fire fighting organization and auxiliary services; fire inspection and investigation; support of volunteer fire forces; and other fire prevention activities. Includes cost of fire fighting facilities, such as fire hydrants and water, furnished by other agencies of the government." These measures come from the United States Census. Census of Government. Volume 4. Government Finances. Number 5, Compendium of Government Finances.

corrections expenditures consists of "state prisons, reformatories, houses of correction, and other state institutions for the confinement and correction 
of convicted persons and juveniles. Includes only state-operated facilities; excludes cost of maintaining prisoners in institutions of other governments." These measures come from the United States Census. Census of Government. Volume 4. Government Finances. Number 5, Compendium of Government Finances.

housing and development expenditures "comprises the functions Natural Resources, Parks and Recreation, Housing and Community Development, Sewerage, and Sanitation Other Than Sewerage." These measures come from the United States Census. Census of Government. Volume 4. Government Finances. Number 5, Compendium of Government Finances.

utilities expenditures includes "government owned and operated water supply, electric light and power, gas supply, or transit system." These measures come from the United States Census. Census of Government. Volume 4. Government Finances. Number 5, Compendium of Government Finances. 


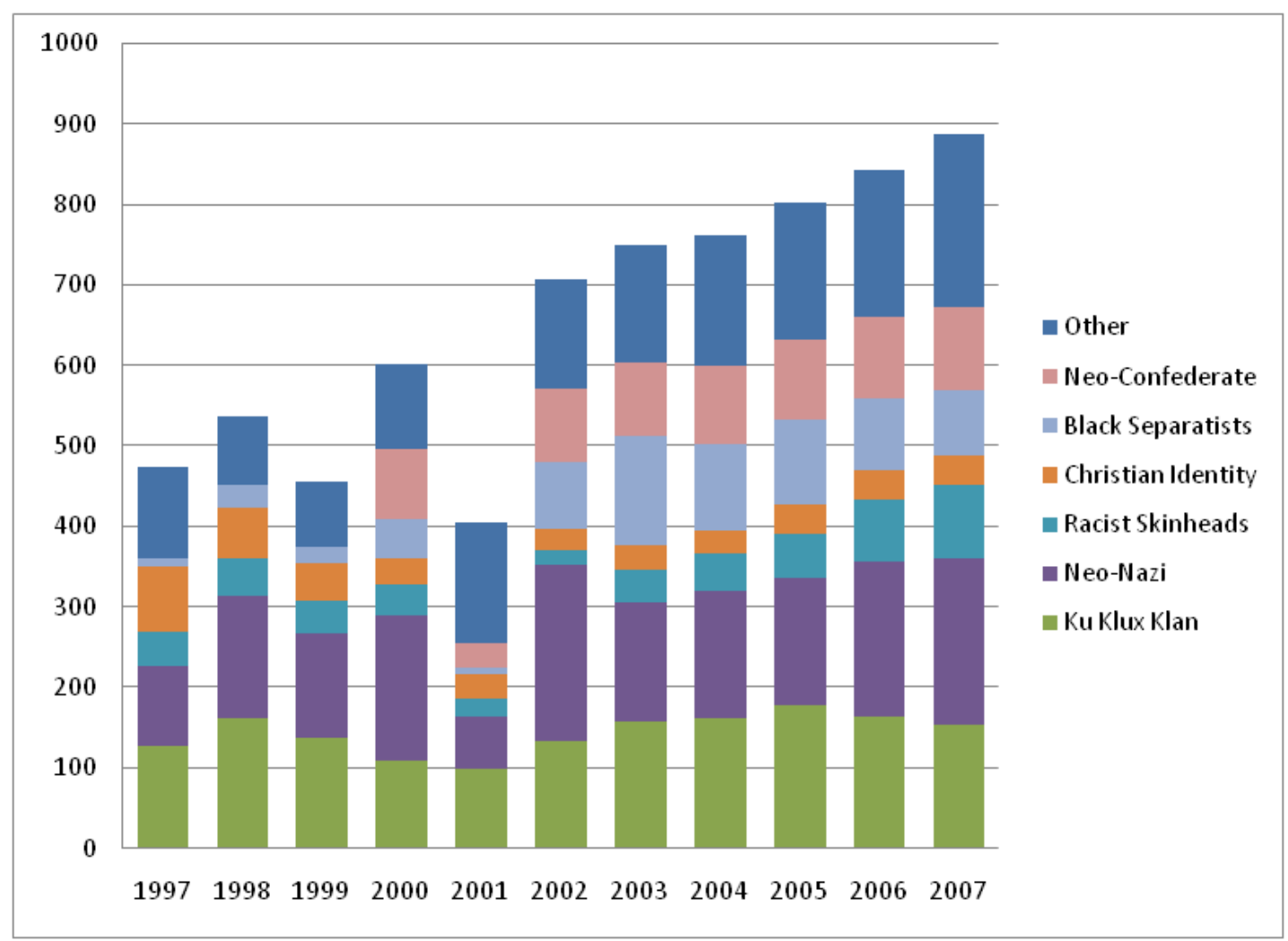

Number of Hate Group Chapters in the United States: 1997 - 2007 


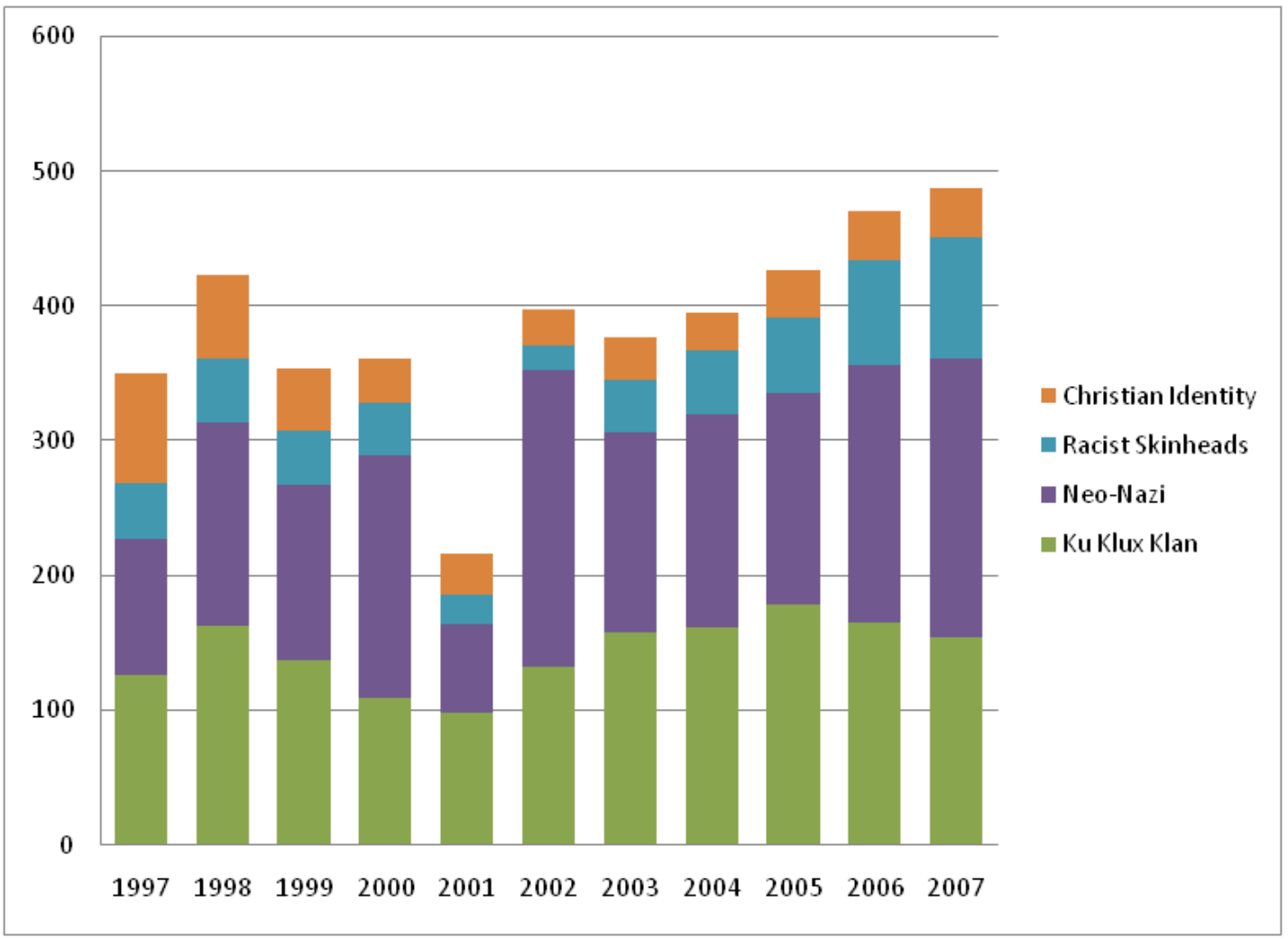

Figure 2: Number of Ku Klux Klan, Neo-Nazi, Skinhead, and Christian Identity Chapters in the US: 1997 - 2007 


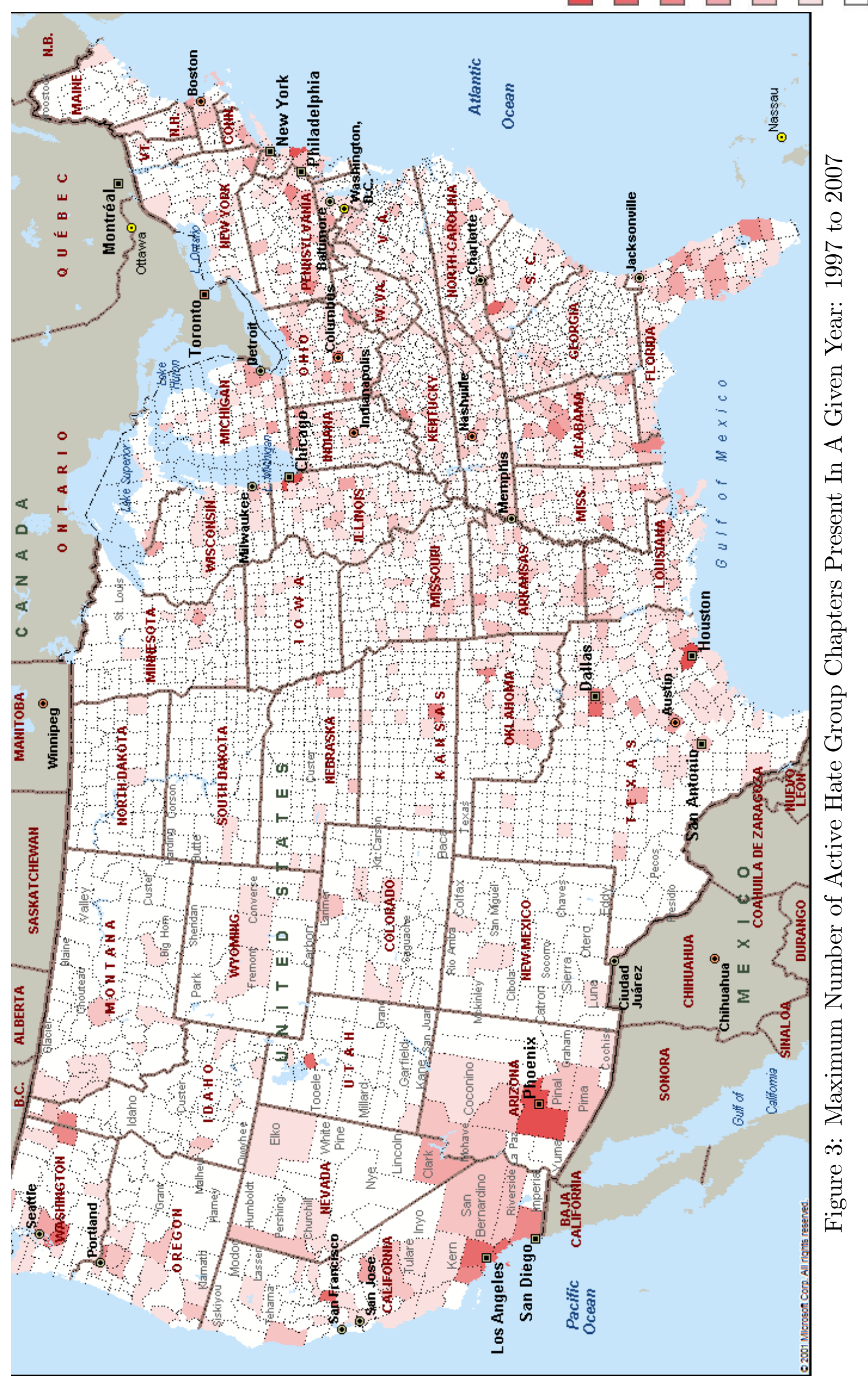




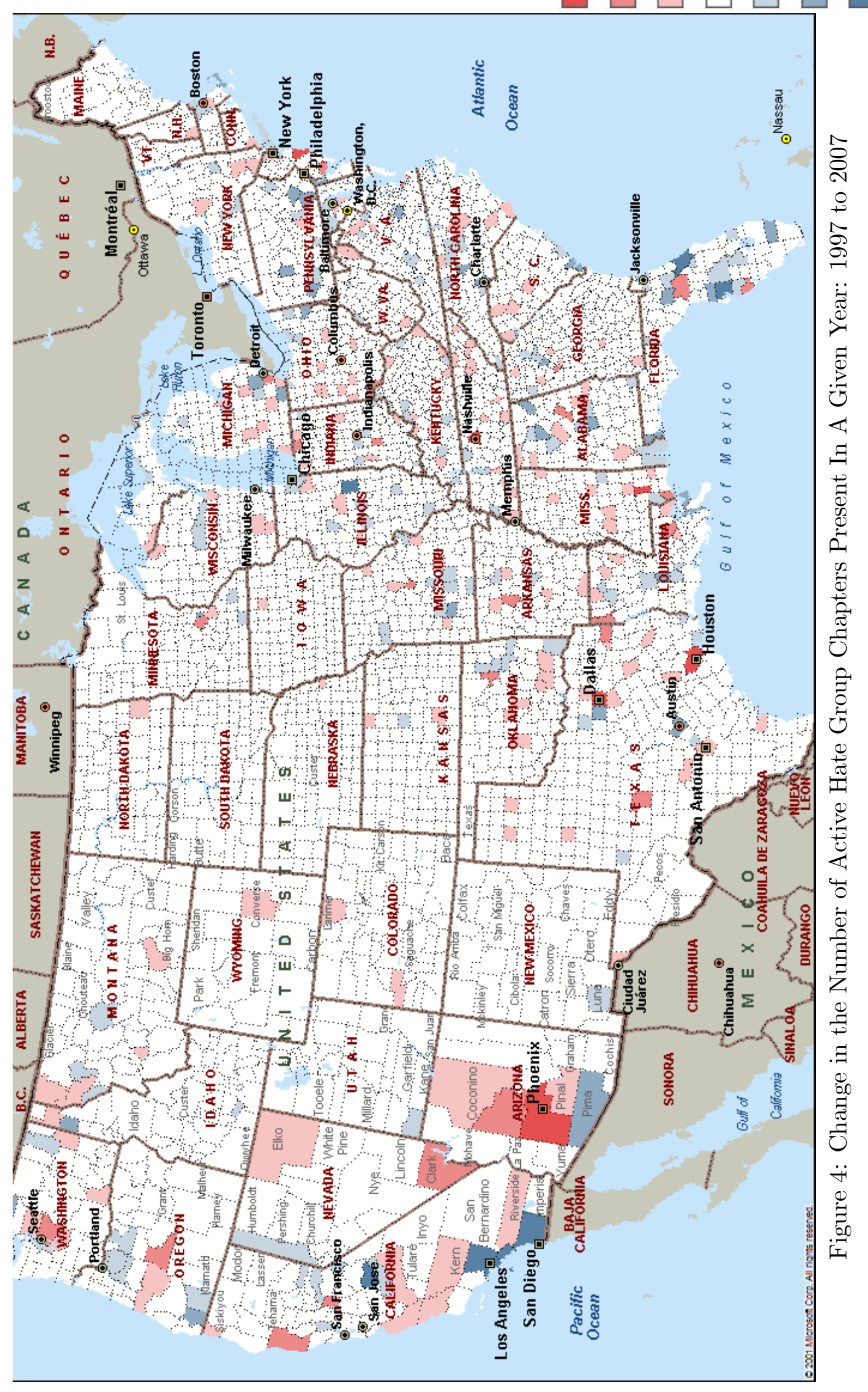




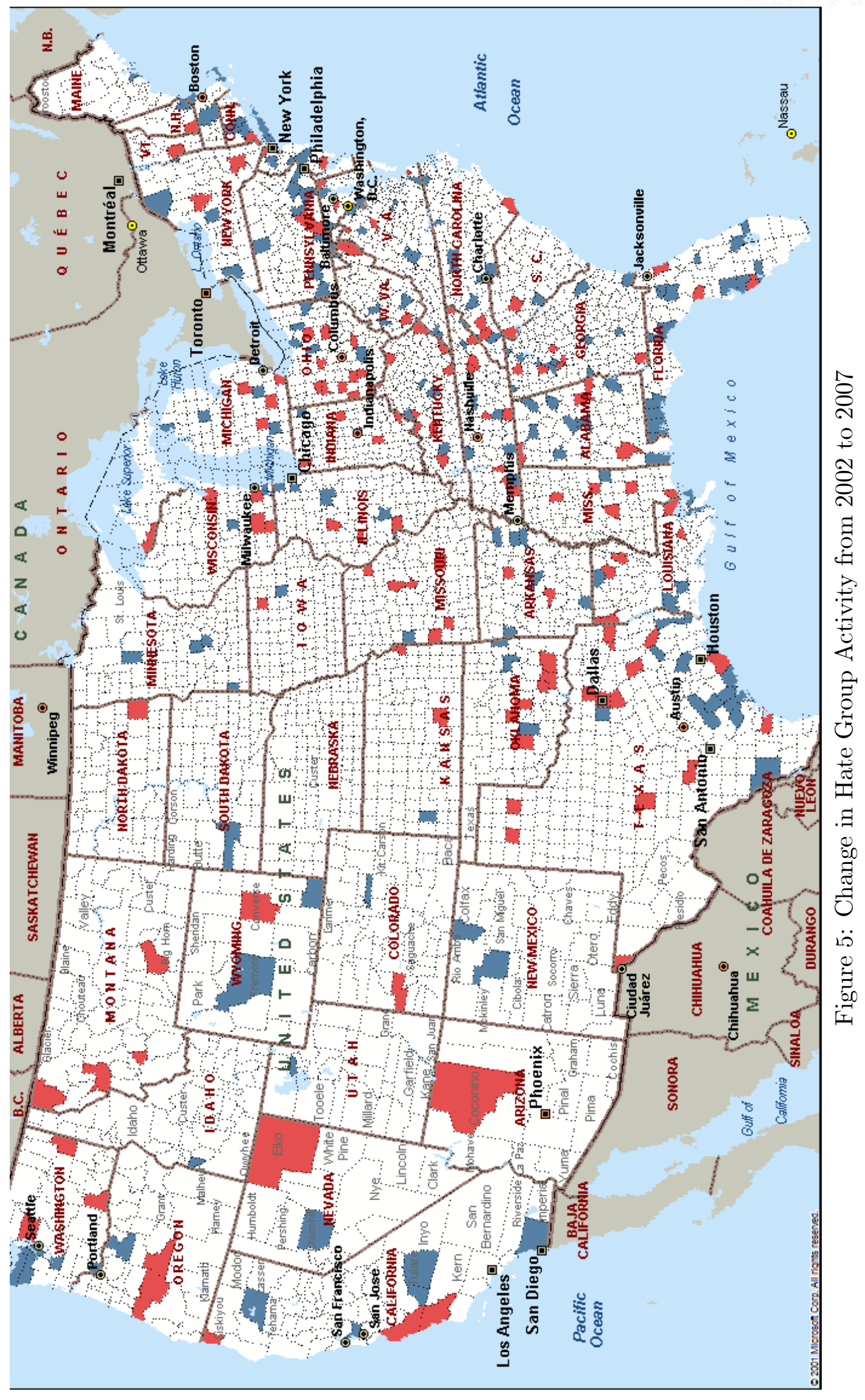




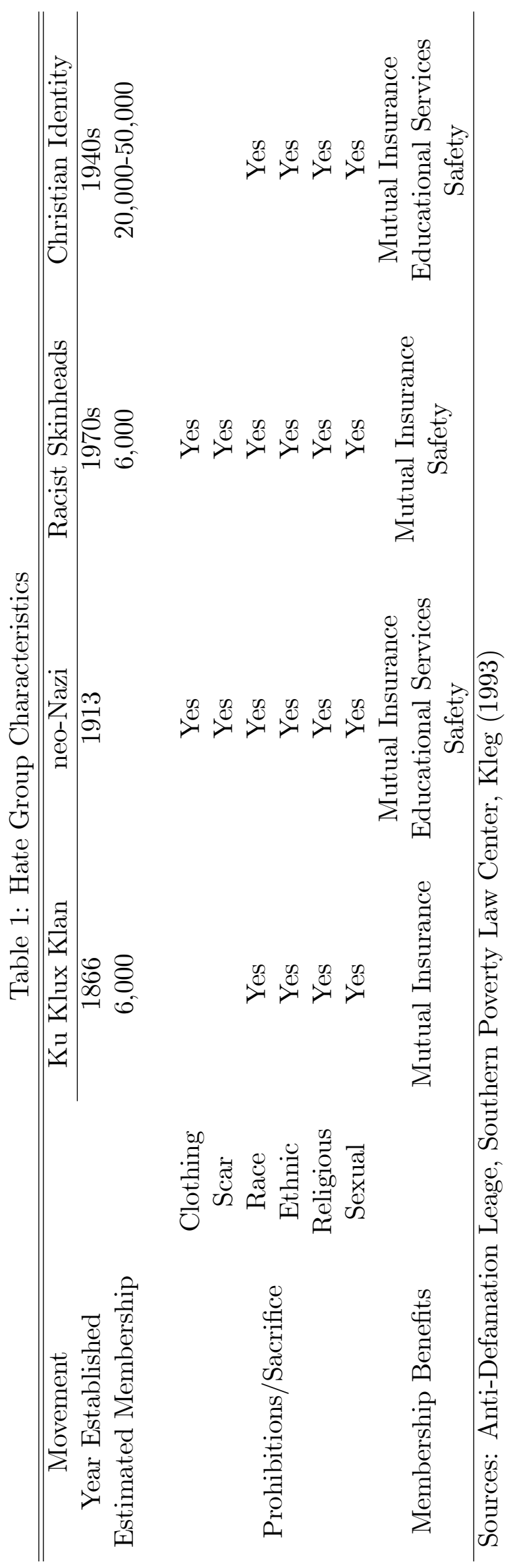




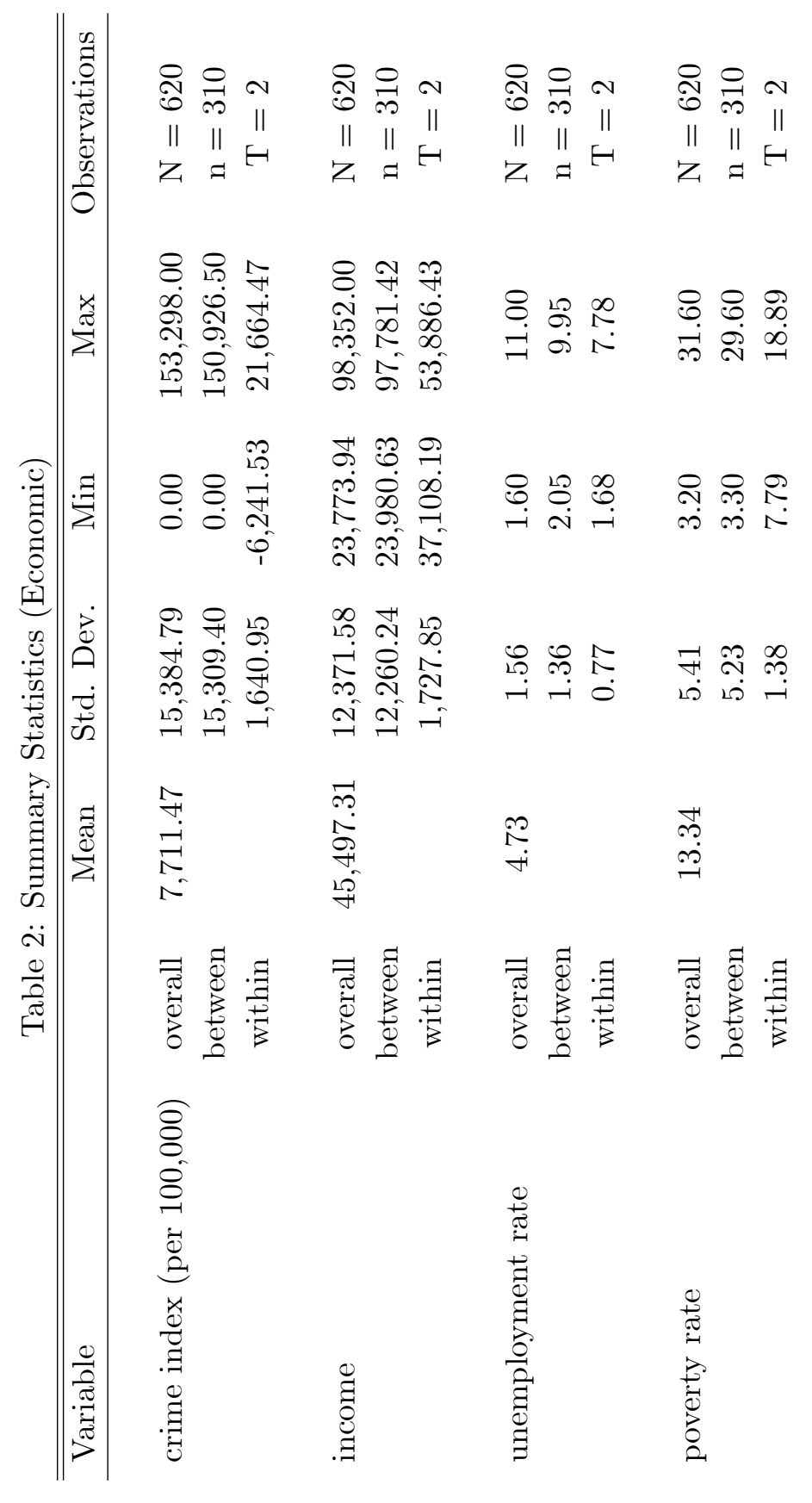




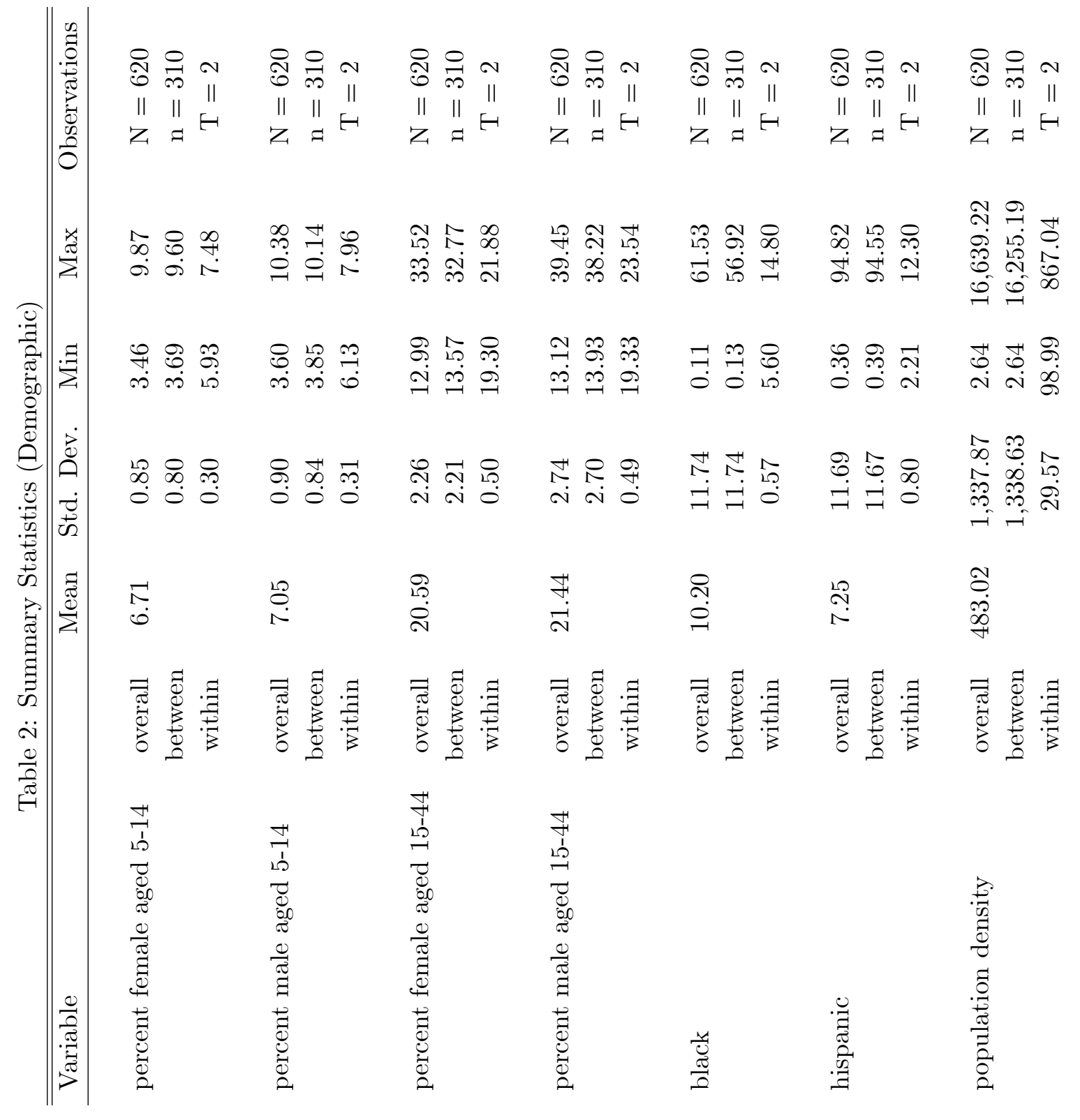




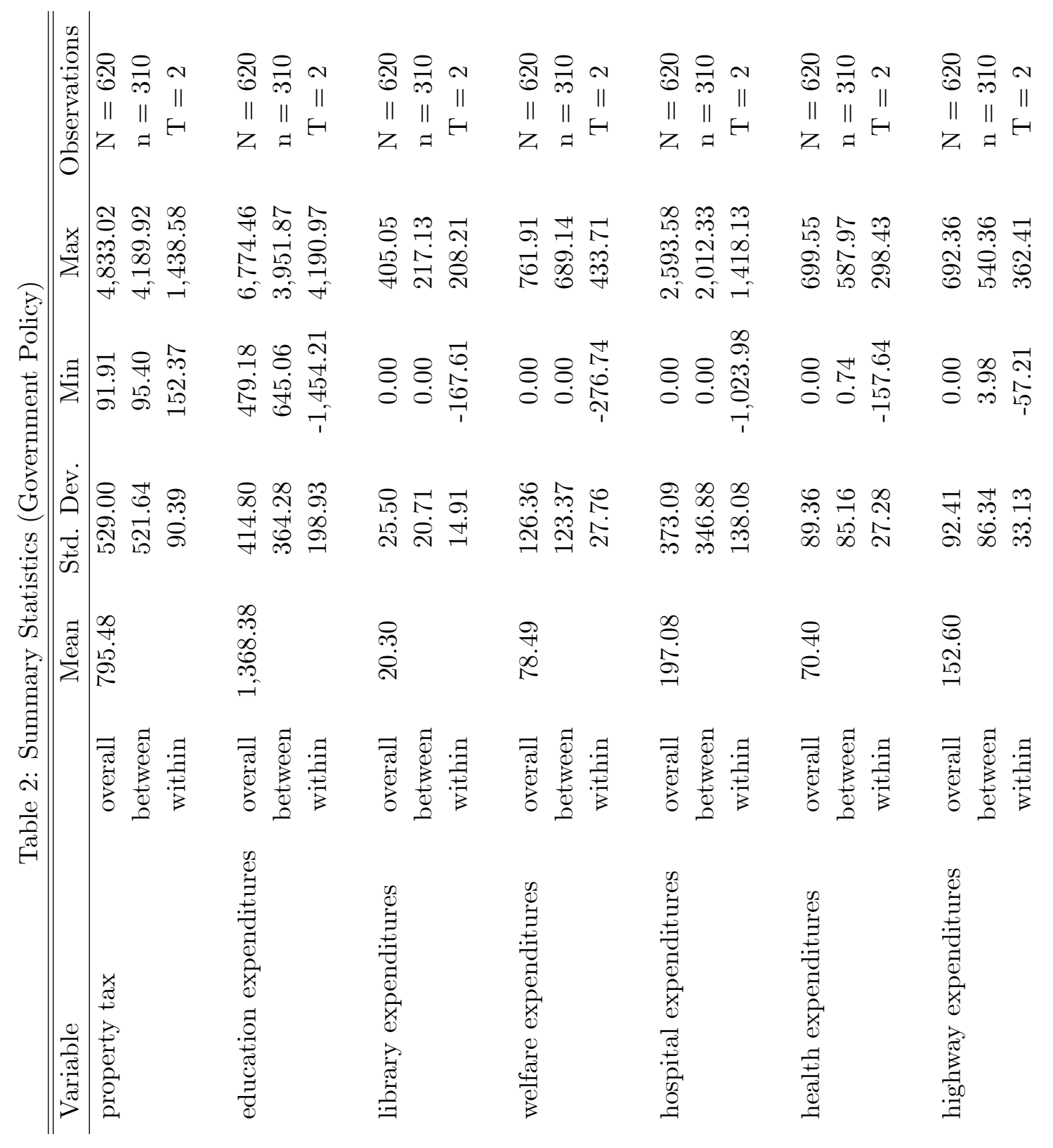




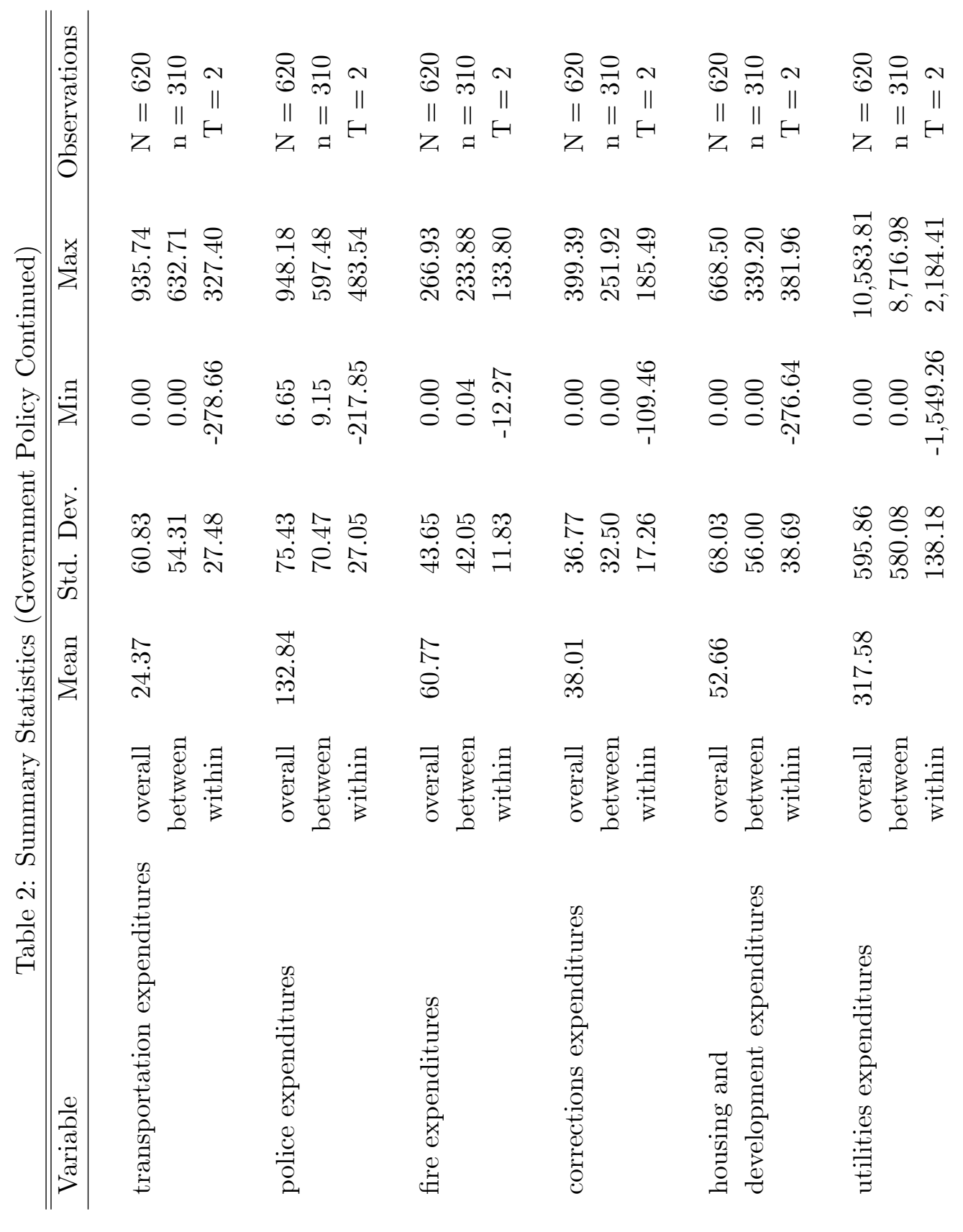




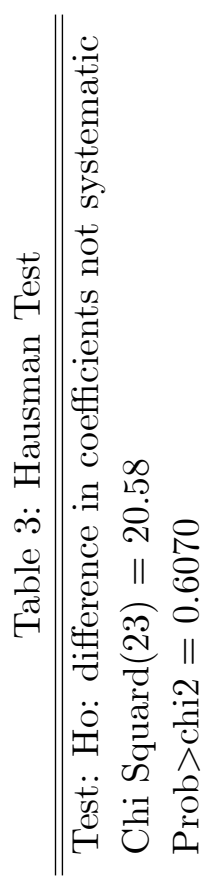




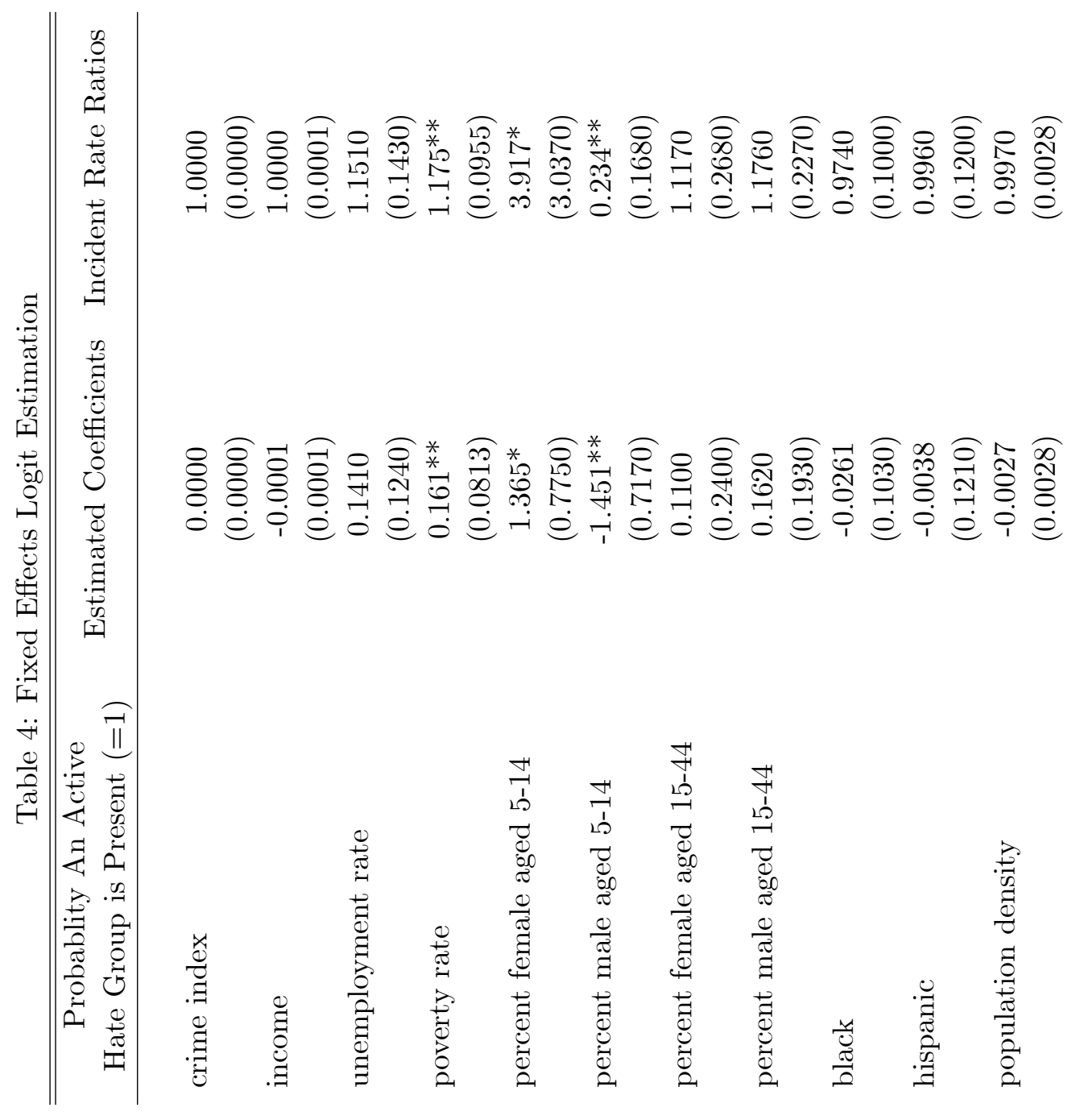




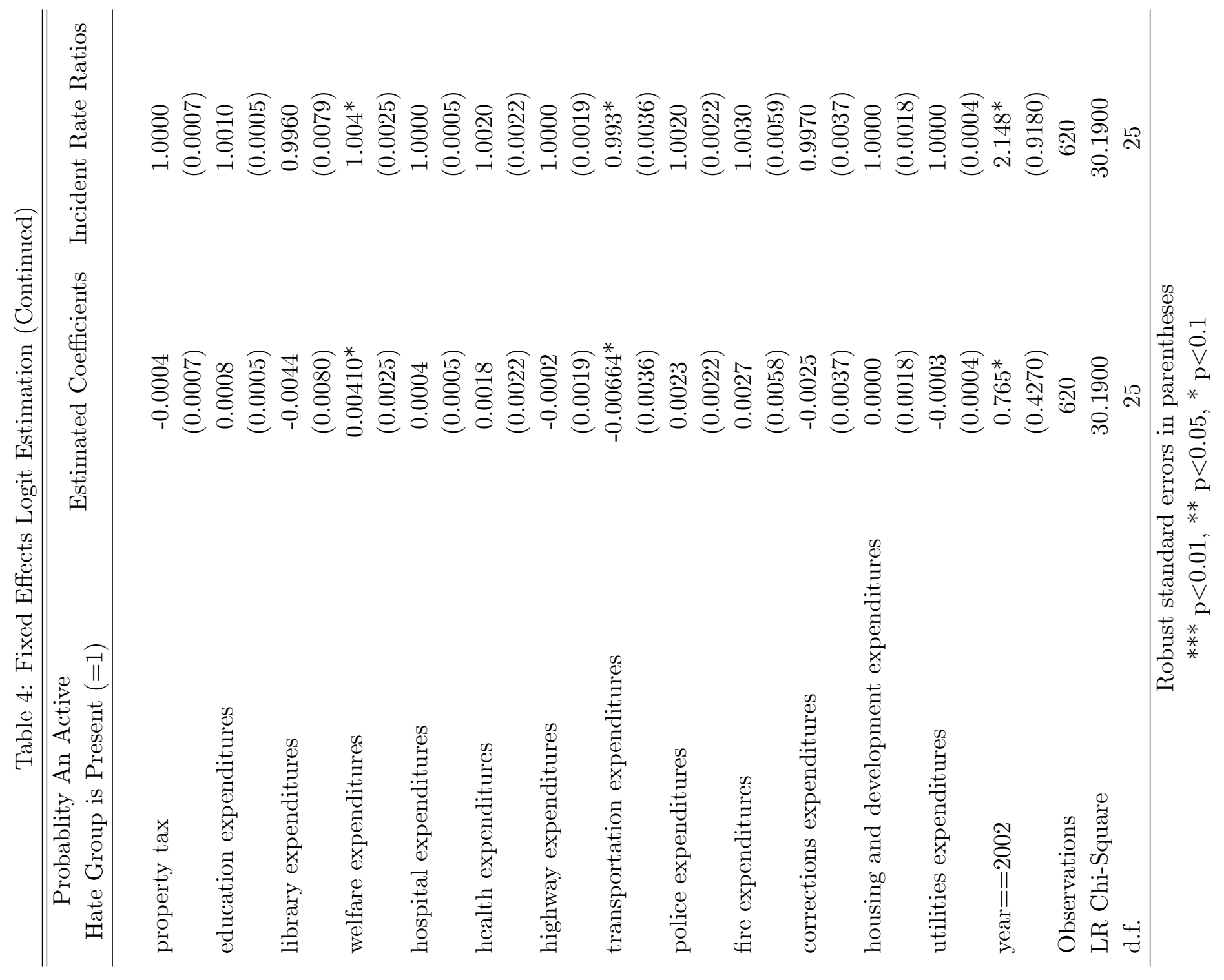

